\title{
Toughening Bismaleimide Resins by $N$-Allyl Aromatic Amine
}

\author{
Guozheng LiANG and Aijuan Gu \\ Department of Chemical Engineering, Northwestern Polytechnical University, \\ Xi'an, Shaan Xi 710072, People's Republic of China
}

(Received March 8, 1996)

\begin{abstract}
N, N^{\prime}$-Diallylaminodiphenyl methane, coded as ADM, was prepared and used to modify 4,4'-bismaleimidediphenyl methane (BDM). Copolymers of BDM and ADM, and composite based on the copolymer were prepared and characterized. Results show that the copolymers and composite have good thermal and mechanical properties as well as hot/wet resistance after postcured at $200^{\circ} \mathrm{C}$ for $6 \mathrm{~h}$. KEY WORDS $\quad N, N^{\prime}$-Diallylaminodiphenyl Methane / Toughening of Bismaleimide / Lowering Postcuring Temperature /
\end{abstract}

High-performance organic matrix composites are considerable lighter than metals and are replacing metals in many aerospace application. Bismaleimide is one of several polymer candidates for use as a matrix for fiber-reinforced composites usable at elevated temperatures. ${ }^{1-5}$ However, there are problems with bismaleimide-type resins: for example, high curing temperature, and brittleness of the polymers because of the high cross-link density obtained in network polymers. There are many methods have been applied to overcome these problems. The ideal concept for improved toughness in a thermoset system is the linear chain extension reaction of the constituents prior to cross-linking. It is well known that the copolymerization of bismaleimide with aromatic diamines results in linear chain extension via a Michael addition reaction. ${ }^{6-8}$ The chain extension of bismaleimides do decreases brittleness, however, also induces a reduction in thermal properties such as decomposition temperature, glass transition temperature $\left(T_{\mathrm{g}}\right)$ and thermal stability. Another typical example is the copolymer of bismaleimide and allyl-type compounds, which is a reasonable explanation for the very high fracture toughness of bismaleimide resin. ${ }^{9-11}$ However, these systems need to be postcured at high temperature such as $220-250^{\circ} \mathrm{C}$.

The main target of authors is therefore the reduction of the curing and the postcuring temperature of bismaleimide and the improvement of fracture toughness of the cured bismaleimide resin with no, or only minor, reduction in the thermal and hot/wet environmental stability. In this paper, a new allyl compound, $N, N^{\prime}$ diallylaminodiphenyl methane (ADM) was synthesized, and the copolymers of 4,4'-bismaleimidodiphenyl methane (BDM) with ADM in various mole ratios were prepared and characterized. The laminate based on the copolymer and glass cloth was prepared, and its properties were also discussed.

\section{EXPERIMENTAL}

\section{Materials}

4,4'-Bismaleimidodiphenyl methane, supplied by $\mathrm{Hu}-$ Bei Fengguang Chemicals (Fgc), China, was purified by recrystallization from $1: 1 \mathrm{CHCl}_{3} / \mathrm{MeOH}$. 4,4'-Diaminodiphenyl methane (DDM) (Fgc) was purified by recrystallization from ethanol. 3-Chloropropylene was obtained from Xi'an Reagents Chemical Plants (Xrcp), China, and was used as supplied. E-PW-220, a kind of isotropic plain woved glass cloth (thickness $=0.2 \mathrm{~mm}$, single diameter $=8 \mu \mathrm{m}$, areal weight $=200 \mathrm{gm}^{-2}$ ), was kindly supplied by Nanjin Fibers Institute, China. It was suface treated by a $1-2 \%$ wt water solution of the compound made up of silane and methyl acrylic chromic oxide complex compound.

\section{Preparation of $A D M$}

3-Chloropropylene $(1.1 \mathrm{~mol})$ was added dropwise to a stirred solution of $4,4^{\prime}$-diaminodiphenyl methane $(0.5$ mol) in ethanol under nitrogen atmosphere at ambient temperature. The solution was stirred and heated at $30-40^{\circ} \mathrm{C}$ for about $4 \mathrm{~h}$. The reaction mixture was poured into a dilute solution of $\mathrm{NaHCO}_{3}$, then with water, and dried to yield ADM.

\section{Preparation of Prepolymers and Neat Resins}

Four different formulations were evaluated to see the effect of differing stoichiometries of each component on the processing and performance parameters and also to establish the formulational latitude this system provides.

The system were:

$\begin{array}{cc}\text { System } & \text { BDM : ADM (weight ratio) } \\ \text { I } & 100: 68 \\ \text { II } & 100: 50 \\ \text { III } & 100: 40 \\ \text { IV } & 100: 30\end{array}$

For each system appropriate quantities of each component were placed in a three necked round bottom glass flask equipped with a mechanical stirring device and thermometer. The contents were heated with stirring and the temperature was maintained between $110-120^{\circ} \mathrm{C}$ until a clear homogeneous melt was obtained. The melt was maintained at $120^{\circ} \mathrm{C}$ for additional $10 \mathrm{~min}$, the resultant liquid is defined as prepolymer.

For the neat resin properties presented in this paper, the prepolymer was degassed while hot at $110^{\circ} \mathrm{C}$ and then poured into the glass molds and cured per the following cure cycles: $150^{\circ} \mathrm{C} / 1 \mathrm{~h}+180^{\circ} \mathrm{C} / 2 \mathrm{~h}+200^{\circ} \mathrm{C} / 6 \mathrm{~h}$. Ordinary convection ovens were used for curing and 
postcuring purposes.

\section{Preparation of Composite}

A $50 \mathrm{w} / \mathrm{o}$ solution of prepolymer III in acetone was used to impregnate E-PW-220 plain woved glass cloth, using brushing impregnation technique. The prepreg was then dried on the rotating drum under a quartz heat lamp to a volatile content of $12-13 \mathrm{wt} \%$. The tapes were then removed from the drum and then cut in plies and stacked in a mold for the compression molding process. The mold was placed in a hydraulic press under contact pressure and the temperature was increased from room temperature to $120^{\circ} \mathrm{C}$ at a $2^{\circ} \mathrm{C} \mathrm{min}{ }^{-1}$ heat-up rate. The prepreg was held at $120^{\circ} \mathrm{C}$ for 20 min under contact pressure. At the end of this period, $0.7 \mathrm{MPa}$ pressure was applied and held for $2 \mathrm{~h}$ at $150^{\circ} \mathrm{C}$ for $1 \mathrm{~h}$, and $180^{\circ} \mathrm{C}$ for $2 \mathrm{~h}$, successively, at these conditions. After that, the mold was cooled slowly to room temperature under pressure. The laminate was demolded and postcured in an air-circulation oven.

\section{Testing}

A standard laboratory hot-plate equipped with a temperature controller was used to determine the prepolymers gel time at various temperature. The time required for the resin to stop stringing and become elastic is called the gel time.

Thermal analysis of samples was carried out on a Du Pont 990 thermal analyzer unit equipped with a Perkin-Elmer DSC differential scanning calorimetric unit and at a heating rate of $10^{\circ} \mathrm{C} \mathrm{min}^{-1}$.

Thermogravimetric analysis (TGA) was conducted with a Perkin-Elmer DEL 7A SERIES TGA 7 in a nitrogen atmosphere at a heating rate of $10^{\circ} \mathrm{C} \mathrm{min}^{-1}$.

Tensile, flexural and impact date of neat resins were obtained according to GB1451-83, GB3356-82, GB104279 , respectively. Heat deflection temperature (HDT) was done by ASTMD 648.

Composite tensile, flexural and impact properties were measured by GB1447-83, GB1449-83 and GB1042-79, respectively. In addition, short beam shear strength (SBS) was done by GB3357-82.

Humidity resistance was measured by putting samples into boiling distilled water, then determining the values of water absorption, HDT of neat resin and SBS strength of composite samples aged for various length of time.

\section{RESULTS AND DISCUSSION}

\section{Synthesis and Characterization of $A D M$}

ADM was synthesized according to the reaction sequences outlined in Scheme 1.

From this scheme, it can be seen that the synthesis of ADM was based on the reaction of DDM with 3chloropropylene. It is well known that primary amine, secondary amine and tertiary amine can all react with 3-chloropropylene, so in order to avoid the reaction of ADM with 3-chloropropylene, the mole ratio of DDM with 3-chloropropylene must be more than $1: 1$. In addition, strong base such as $\mathrm{NaOH}$ may be used to prohibite the reaction of $\mathrm{HCl}$ with amine.

Table I lists typical physical properties of ADM and DDM, it can be seen that ADM was a brown-red transparent liquid at room temperature with a viscosity of $0.22 \mathrm{~Pa} \mathrm{~s}^{-1}$, while DDM was a pale yellow crystal at room temperature with a melting point of $90-92^{\circ} \mathrm{C}$. In addition, both ADM and DDM have excellent solubility in ordinary low boiling point solvent, such as acetone, alcohol, etc. So allylization can greatly change the properties of DDM, and these change are good to improve the prepolymerization processing of BDM with aromatic amine.

Although ADM has unsaturated double bond, it is difficult to selfpolymerization. Experimental showed that viscosity of ADM does not significantly change after ADM was heated up to $200^{\circ} \mathrm{C}$ for several hours. Besides that, typical physical properties (such as room temperature viscosity, color, and solubility in acetone, alcohol, etc.) of ADM synthesized in situ and the properties of ADM storaged at room temperature for one year are almost the same.

On the other hand, ADM is a good co-reaction monomer of BDM, this is because bismaleimides possess two double bonds, which are highly electron poor duing to the two flanking inside carbonyl groups. Therefore, $\mathrm{BDM}$ can be involved in a copolymerization reaction with ADM.

\section{Properties of Prepolymers I-IV}

Table II presents physical properties of prepolymers I-IV, it can be seen that prepolymers are red transparent solid at room temperature, with low softening point $\left(<30^{\circ} \mathrm{C}\right)$. The higher the BDM/ADM, the higher the softening point. Four prepolymers can all be solube in acetone and all the solutions have good storage stability at room temperature. After stored for 30 days,

Table I. Typical physical properties of ADM and DDM

\begin{tabular}{lcc} 
& ADM & DDM \\
\hline $\begin{array}{c}\text { Surface appearance } \\
\left(25^{\circ} \mathrm{C}\right)\end{array}$ & $\begin{array}{c}\text { Brown-red transparent } \\
\text { liquid }\end{array}$ & $\begin{array}{c}\text { Pale yellow } \\
\text { crystal }\end{array}$ \\
$\mathrm{mp} /{ }^{\circ} \mathrm{C}$ & - & $90-92$ \\
$\mathrm{Viscosity}\left(25^{\circ} \mathrm{C}\right) / \mathrm{Pa} \cdot \mathrm{s}$ & 0.22 & - \\
Solubility & Can solube in acetone, ethanol \\
Typical allyl & 29.2 & - \\
concentration $/ \%$ & & \\
\hline
\end{tabular}

Table II. Physical properties of prepolymers I-IV

\begin{tabular}{lccccc}
\hline & I & II & III & IV \\
\hline Surface appearance & \multicolumn{4}{c}{ Red transparent solid } \\
Softening point $/{ }^{\circ} \mathrm{C}$ & $<10$ & $<10$ & 15 & 30 \\
Melt viscosity at $130^{\circ} \mathrm{C} / \mathrm{Pa} \cdot \mathrm{s}$ & - & & - & 1.81 & 3.25 \\
Solubility in acetone $\left(25^{\circ} \mathrm{C}\right)$ & & & Very good & \\
Storage length of $50 \mathrm{w} / \mathrm{o}$ & & \multicolumn{2}{c}{$>30$} \\
$\quad$ prepolymer in acetone $/$ day & & & &
\end{tabular}
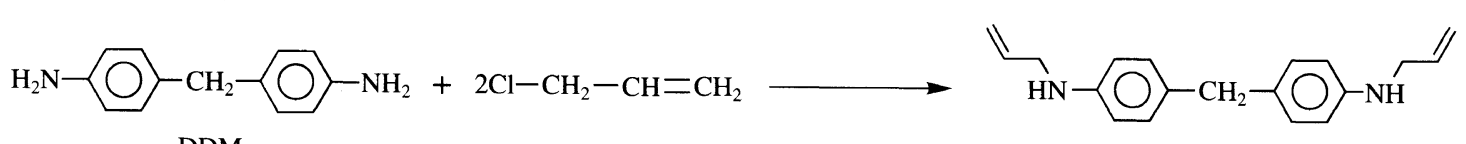

ADM 
no materials settled out of the solutions, so the prepreg based on these prepolymers can be fabricated by solvent technique.

Figure 1 is plots of gel time $v s$. temperature for prepolymers described in this paper. It can be seen that their gel time are longer than $130 \mathrm{~min}$ when the temperature is lower than $130^{\circ} \mathrm{C}$, this suggests that all of them have long pot life at toom temperature. With the temperature increases, the gel time reduce sharply when the temperature is $200^{\circ} \mathrm{C}$, the gel time is within 4-12 min.

Figure 2 is typical DSC thermogram of prepolymers III. It shows that prepolymer III have wide and flat exotherm. This indicates that its curing reaction is moderate, so it is good for obtaining an uniform network with less residual stress of both neat resins and composites. To compare the curing behavior of prepolymers, several thermal characteristics were determined from their DSC traces. Particularly, the onset temperature $\left(T_{1}\right)$ for the polymerization reaction, the exothermic peak temperature $\left(T_{\text {exo }}\right)$, and the temperature for completion of polymerization $\left(T_{2}\right)$ were determined. The $T_{1}$ and $T_{2}$ were obtained by extrapolating the front side and the base line of the DSC trace. The results are listed in Table III, the relative reactivity of prepolymers may be judged on the basis of $T_{\text {exo }}$ values. It is seen that the higher BDM/ADM ratio, the higher the curing temperature. Thus, the polymerization of $\mathrm{BDM} / \mathrm{ADM}$ systems was shifted to higher temperatures when the concentration of BDM was increased. On the other hand, the $T_{\text {exo }}$ of $\mathrm{BDM} / \mathrm{ADM}$ systems is $16-38^{\circ} \mathrm{C}$ lower than that of $\mathrm{BDM} / \mathrm{B}-\mathrm{A}\left(O, O^{\prime}\right.$-diallylbisphenol $\left.\mathrm{A}\right)$, so the relative order of reactivity of $\mathrm{BDM} / \mathrm{ADM}$ systems and $\mathrm{BDM} / \mathrm{B}-\mathrm{A}$ was $\mathrm{BDM} / \mathrm{ADM}>\mathrm{BDM} / \mathrm{B}-\mathrm{A}$.

The curing mechanism is complex. It includes the addition of maleimide and allyl, and that of maleimide and amine as well as the anionic imide oligomeriza-

Table III. DSC data of prepolymers

\begin{tabular}{lccc}
\hline Prepolymer & $T_{1} /{ }^{\circ} \mathrm{C}$ & $T_{\text {exo }} /{ }^{\circ} \mathrm{C}$ & $T_{2} /{ }^{\circ} \mathrm{C}$ \\
\hline I & 153.1 & 216.2 & 262.1 \\
II & 158.2 & 219.7 & 268.3 \\
III & 163.0 & 222.4 & 272.4 \\
IV & 178.9 & 228.1 & 281.0 \\
BDM/B-A & 215.5 & 254.2 & 296.1 \\
\hline
\end{tabular}

${ }^{\mathrm{a}}$ The sample was prepared by mixing BDM and $\mathrm{B}-\mathrm{A}$ in mole ratio of $1: 0.87$ and heating at $120^{\circ} \mathrm{C}$ until a transquent liquid was obtained. tion. ${ }^{10,12}$

\section{Properties of Neat Resins}

Table IV shows properties of neat resins, it can be seen that the ratio of $\mathrm{BDM} / \mathrm{ADM}$ has great effect on the thermal and mechanical properties. Systems III and IV have better thermal and mechanical properties than systems I and II. The superior thermal and mechanical properties of the copolymers probably result from the better control of the crosslinking density. On the other hand, the postcure cycle has insiginatantly change to the properties. After postcured at $200^{\circ} \mathrm{C}$ for $6 \mathrm{~h}$, systems III and IV have excellent intergret properties, and they are similar to that of BDM/B-A, which must be postcured at the temperature of $220^{\circ} \mathrm{C}$ for $12 \mathrm{~h}$.

The thermal stability of the cured resins was also ascertained by dynamic thermogravimetric analysis in nitrogen atmosphere. Figure 3 shows primary TGA

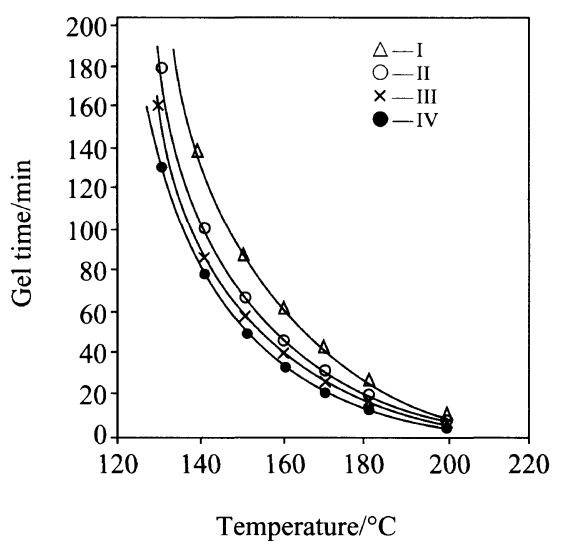

Figure 1. Plots of gel time vs. temperature for prepolymers I-IV.

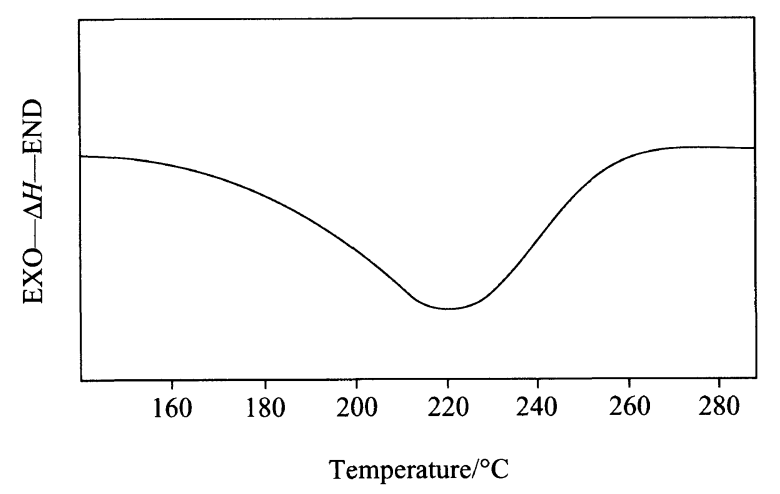

Figure 2. Typical DSC thermograms of prepolymers I and II.

Table IV. Properties of neat resins

\begin{tabular}{|c|c|c|c|c|c|c|c|c|}
\hline & I & II & II & III & III & IV & IV & $\mathrm{BDM} / \mathrm{B}-\mathrm{A}^{*}$ \\
\hline Postcure cycle & $\mathrm{b}$ & $\mathrm{a}$ & $\mathrm{b}$ & $\mathrm{a}$ & $\mathrm{b}$ & $\mathrm{a}$ & $\mathrm{b}$ & $\mathrm{b}$ \\
\hline $\mathrm{HDT} /{ }^{\circ} \mathrm{C}$ & 143 & 204 & 201 & 264 & 278 & 263 & 252 & 268 \\
\hline Flexural strength/MPa & 87 & 93 & 106 & 146 & 131 & 149 & 154 & 107 \\
\hline Impact strength $/ \mathrm{kJ} \mathrm{m}^{-2}$ & 7.1 & 8.2 & 9.1 & 11.8 & 15.6 & 11.8 & 13.0 & 13.5 \\
\hline \multicolumn{9}{|l|}{ Tensile } \\
\hline Strength/MPa & - & - & - & 87.2 & 86.4 & 82.5 & 81.3 & 78.4 \\
\hline Elongation $/ \%$ & - & - & - & 3.0 & 3.2 & 2.9 & 3.1 & 2.7 \\
\hline$T_{\text {IWL }} /{ }^{\circ} \mathrm{C}$ & - & - & - & 475 & - & 477 & - & 425 \\
\hline$P D T_{\max } /{ }^{\circ} \mathrm{C}$ & - & - & - & 523 & - & 528 & - & 447 \\
\hline$Y_{\mathrm{c}}\left(800^{\circ} \mathrm{C}\right) /{ }^{\circ} \mathrm{C}$ & - & - & - & 38.0 & - & 38.3 & - & $21.2^{* *}$ \\
\hline
\end{tabular}

a, postcure cycle is $200^{\circ} \mathrm{C} / 6 \mathrm{~h} ; \mathrm{b}$, postcure cycle is $220^{\circ} \mathrm{C} / 12 \mathrm{~h}$. ${ }^{*}$ The mole ratio of $\mathrm{BDM}$ and $\mathrm{B}-\mathrm{A}$ is $1: 0.87 . * * \mathrm{The}$ char yield at $700^{\circ} \mathrm{C}$. 


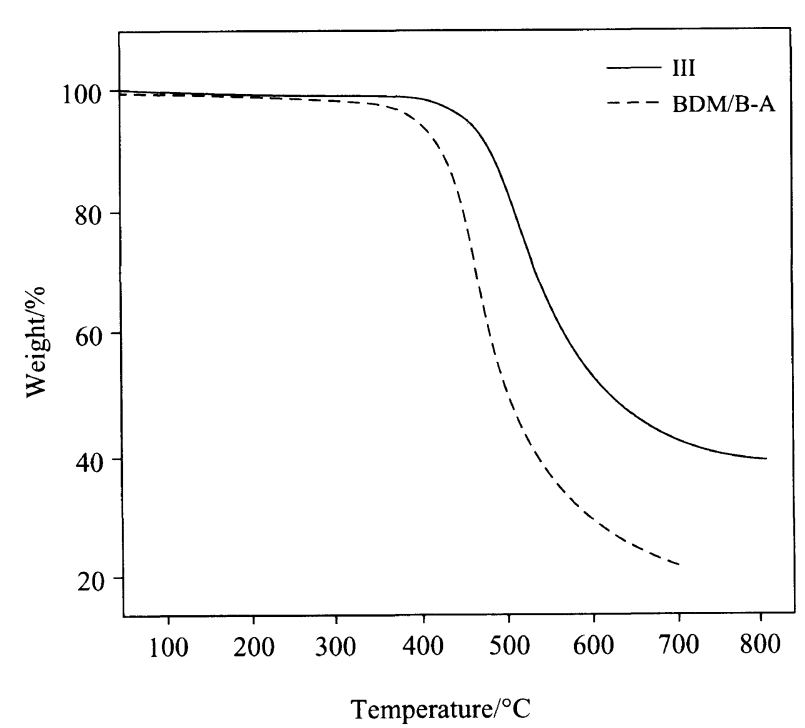

Figure 3. Thermogravimetric analysis of cured system III and $\mathrm{BDM} / \mathrm{B}-\mathrm{A}$ resins.

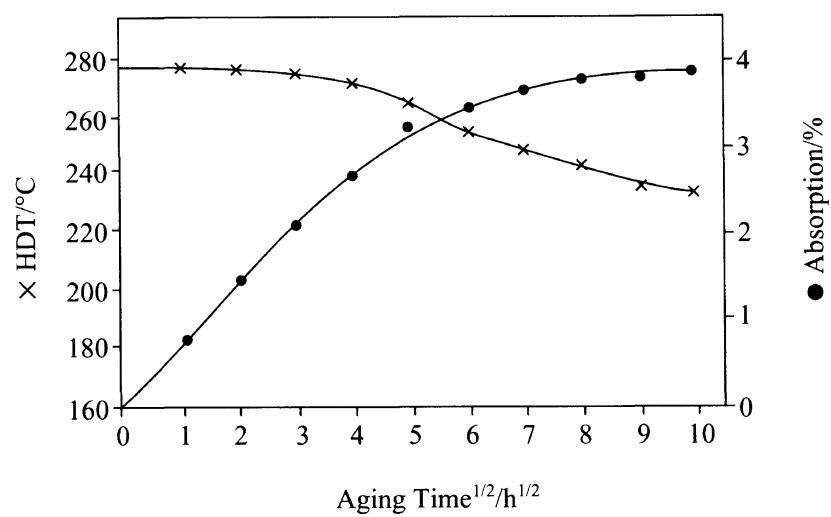

Figure 4. Water absorption-HDT-time correlation of cured resin III.

thermograms of the cured system III and BDM/B-A resins in nitrogen. The temperature of initial weight loss $\left(T_{\mathrm{IWL}}\right)$, the maximum polymer decomposition temperature $\left(P D T_{\text {max }}\right)$ and the char yield $\left(Y_{\mathrm{c}}\right)$ at $800^{\circ} \mathrm{C}$ were determined from the TGA traces and are listed in Table IV. It indicates that BDM/ADM has very good thermal stability, and which is better than that of BDM/B-A system.

Highly cross-linked thermosetting bismaleimide resins normally show high moisture absorption, therefore, their wet HDT is soimetimes significantly reduced when saturated with moisture. The moisture absorption and HDT were studied for system III showed in Figure 4. Neat resin samples were aged in boiling distilled over a period of $100 \mathrm{~h}$, the weight increase and HDT then measured. After aging for $100 \mathrm{~h}$, system III shows a moisture absorption of $3.9 \%$ by weight, and HDT was $220^{\circ} \mathrm{C}$, which is $82.7 \%$ of the dry value. These data suggest that system III has excellent hot/wet resistance, which may be contribute to the fewer hydrophilous groups in its chemical structure and its thermal aromatic network with less residual stress.

\section{Properties of Composite}

Table $\mathrm{V}$ gives property of composite based on system III. Overall, these properties are very good, especially the strength and the strength retention at elevated
Table V. Properties of composites based on system III and $\mathrm{BDM} / \mathrm{B}-\mathrm{A}$

\begin{tabular}{|c|c|c|}
\hline & System III & $\mathrm{BDM} / \mathrm{B}-\mathrm{A}$ \\
\hline \multicolumn{3}{|l|}{ Tensile } \\
\hline Strength/MPa & 662 & 680 \\
\hline Modulus/GPa & 37 & 39 \\
\hline Elongation $/ \%$ & 2.7 & 2.4 \\
\hline Flexural strength/MPa & 620 & 631 \\
\hline \multicolumn{3}{|l|}{ SBS strength/MPa } \\
\hline Dry & 52.4 & 58 \\
\hline Wet $^{\mathbf{a}}$ & $39.0(75.4)$ & $46.5(78.3 \%)$ \\
\hline Impact strength $/ \mathrm{kJ} \mathrm{m}^{-2}$ & 136 & 141 \\
\hline Resin content $/ \%$ & 33.6 & 34 \\
\hline
\end{tabular}

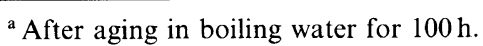

temperature and hot/wet condition. In the case of SBS strength, when tested at $180^{\circ} \mathrm{C}$ and $200^{\circ} \mathrm{C}, 85.8 \%$ and $70.2 \%$ of the original room temperature is retained, respectively. A similar type SBS strength retention $(75.4 \%)$ is noted after aging in boiling distilled water for $100 \mathrm{~h}$.

\section{CONCLUSIONS}

$N, N^{\prime}$-Diallylaminodiphenyl methane (ADM) is a new type comonomer for bismaleimide resins. The new monomer is prepared by allylization of $N, N^{\prime}$-diaminodiphenyl methane (DDM), after curing and postcuring at relative lower temperature $\left(<200^{\circ} \mathrm{C}\right)$. BMI/ADM resin and its composites have outstanding performance characteristics comparable with $O, O^{\prime}$-diallyl-bisphenol A modified BMI resin which must be postcured at the higher temperature such as $220^{\circ} \mathrm{C}$ or $250^{\circ} \mathrm{C}$, for $6-12$ hours.

\section{REFERENCES}

1. M. A. Chaudhari, In "Looking Ahead for Materials and Processes," J. de Bossu, G. Briens, and P. Lissas Ed., Amsterdam: Elsevier Science Publishers, Amsterdam, 1987, pp 469-483.

2. Stephen B. Driscoll and T. C. Walton, SAMPE J., July/August, 9-17 (1987).

3. S. Jin and A. F. Yee, J. Appl. Polym. Sci., 43, 1849 (1991).

4. K. A. Barrett, B. Fu, and A. Wang, Proceedings, 35th International SAMPE Symposium, "Adv. Mater.: Challenge Next Decade," Society for the Advancement of Materials and Process Engineering, California, 1990, pp 1007-1020.

5. H. D. Stenzenberger and P. Konig, High Perform. Polym., (2), 133-136 (1989).

6. J. K. Varma, Sangita, and D. S. Varms, J. Polym. Sci., Polym. Chem. Ed., 22, 1419 (1984).

7. J. E. White, M. D. Scais, and D. A. Snider, J. Appl. Polym. Sci., 29, 891 (1984).

8. H. D. Stenzenberger, "Structural Adhesives: Developments in Resin and Primers, A. J. Kinloch, Ed., Elsevier Applied Science, Amsterdam, 1986, pp 77-126.

9. G. Liang, L. Lan, and A. Gu, ACTO of Composites, 12(1), 1 (1995).

10. J. J. King, M. Chaudhari, and S. Zahir, Proceedings, 29th National SAMPE Symposium, "Technol. Vectors," Society for the Advancement of Materials and Process Engineering, California, 1984, pp 392-408.

11. K. A. Barret, M. A. Chaudhair, and B. H. Lee, Proceedings, 33rd International SAMPE Symposium, "Mater.-Pathway Future," Society for the Advancement of Materials and Process Engineering, California, 1984, pp 392-406.

12. T. M. Donnellan and D. Roylance, Polym. Eng. Sci., 32(6), 409 (1993). 